\title{
RELACIONAMENTOS SUGAR E A PREOCUPAÇÃO DE QUE O INVESTIMENTO ECONÔMICO POSSA CONFIGURAR ERRONEAMENTE UNIÃO ESTÁVEL OU HOMOAFETIVA
}

\author{
Laira Carone Rachid Domith* \\ Brener Duque Belozi ${ }^{* *}$
}

\begin{abstract}
RESUMO: Nos relacionamentos sugar as pessoas se unem tendo como pré-requisito que uma delas sustente a outra, parcial ou integralmente. Configurada a dependência econômica, caso o relacionamento seja público e duradouro, corre-se o risco de ser interpretado como união estável ou homoafetiva mesmo ausente o ânimo de constituir família. Portanto, a reflexão sobre a validade dos contratos de namoro ganha fôlego. O objetivo deste estudo é demonstrar a importância da celebração do contrato de relacionamento sugar para que, diante do caso concreto, a dependência econômica seja afastada enquanto um dos elementos a configurar vínculo capaz de gerar efeitos assistenciais e sucessórios.
\end{abstract}

PALAVRAS-CHAVE: Relacionamentos sugar; Investimento financeiro; Affectio familiae; Princípio da afetividade; Efeitos jurídicos.

\section{SUGAR RELATIONSHIPS AND THE PREOCCUPATION THAT THE FINANCIAL INVESTMENT MAY DECEITFULLY LEAD TO STABLE OR HOMOAFFECTIVE UNION}

\begin{abstract}
In the sugar relationships, it is previously required that one provides financial support to the other. Once there is economic reliance, and the relationship is public and longlasting, there is the risk that stable or homoaffective union be caracterized. Therefore, the reflection about dating contract takes place. This paper aims at demonstrating the importance of a sugar relationship contract in order to avoid the bond that creates supporting and bequesting effects.
\end{abstract}

\footnotetext{
* Mestre em Direito Público e Evolução Social (UNESA); Professora de Direito de Família da Faculdade Doctum de Juiz de Fora; Advogada

** Mestre em Hermenêutica e Direitos Fundamentais (UNIPAC); Especialista em Direito Empresarial e Econômico pela UFJF; Professor de Direito Civil e Processual Civil da Faculdade Doctum de Juiz de Fora; Advogado
} 
KEYWORDS: Sugar relationships; Financial investment; Affectio familiae; Affectivity principle; Legal effects.

\section{INTRODUÇÃO}

Há algum tempo, a expressão “sugar baby” era usada para designar carinhosamente alguém como “namoradinha”. Atualmente, contudo, ganhou outra conotação com o surgimento dos relacionamentos sugar, passando a compor este universo ao lado de outras duas figuras: sugar daddy e sugar mammy. Tais relacionamentos baseiam-se no investimento patrimonial de homens ou mulheres em troca de uma relação amorosa.

É a legitimação, sem pudores, dos relacionamentos lastreados no interesse financeiro de uma das partes (sugar baby), normalmente pactuados através de avença firmada por pessoas que usam as redes sociais para buscarem um par que atenda aos seus anseios.

O site $\underline{w w w . s o m o s s u g a r . c o m . b r ~ e x p l i c a ~ o ~ m o t i v o ~ d a ~ u t i l i z a c ̧ a ̃ o ~ d o ~ t e r m o ~ s u g a r ~ p a r a ~}$ definir esta modalidade de relacionamento: ao que parece, o norte-americano Adolph Spreckels Bernard, empresário rico, culto e que comandava a companhia Spreckels Sugar Company (maior refinaria de açúcar dos Estados Unidos), após o termino de um casamento fracassado, se envolveu com Alma de Bretteville, uma bela e encantadora jovem 24 anos mais nova que ele. Após um noivado de cinco anos casaram-se em 1908 e tiveram três filhos. Em razão do marido ocupar a Presidência desta empresa e da diferença de idade entre ambos, Alma chamava-o de “sugar daddy” (papai de açúcar).

Segundo explica o site www.meupatrocinio.com que, no Brasil, proporciona o contato entre pessoas maiores de idade que querem este tipo de relação, o estilo de vida sugar tem como pilares os valores da honestidade e da transparência. De acordo com palavras usadas por esta página na web, “nossos membros sabem quem são, o que querem e aquilo que merecem (o melhor que o mundo tem a oferecer, é claro!)”, buscam isso em um relacionamento que lhes oferte apoio emocional, intelectual e financeiro, e manifestam abertamente suas expectativas através de acordos pré-estabelecidos, com previsão de benefícios mútuos, sem se sentirem culpados por seus desejos e intenções.

Tais relacionamentos não podem ser confundidos com prostituição. Inclusive, nos sites que promovem este tipo de relação é vedada a publicação de qualquer material que possa 


\section{RELACIONAMENTOS SUGAR E A PREOCUPAÇÃO DE QUE O INVESTIMENTO ECONÔMICO POSSA CONFIGURAR ERRONEAMENTE UNIÃO ESTÁVEL OU HOMOAFETIVA}

ser considerado obsceno/pornográfico na tentativa de dela afastar a ideia de prostituição ou de agenciamento de acompanhantes.

Embora casamentos “arranjados” com o intuito de aquisição patrimonial tenham sido corriqueiros no passado, na contemporaneidade, com a valorização do amor como elemento fundante dos relacionamentos, o descortinamento do interesse patrimonial passou a ser motivo de constrangimento entre os enamorados. Contudo, nos relacionamentos sugar, aquele que fará o investimento financeiro no outro parceiro tem plena consciência disso ao assumir este tipo de relação e parte da crença de que "o dinheiro não elimina o vínculo que duas pessoas dividem, ao contrário, ele o fortalece” (www.meupatrocinio.com).

O propósito das partes é construir um relacionamento que pode ou não evoluir de um namoro para um casamento, união estável ou homoafetiva. A grande questão que se coloca neste contexto é a dificuldade da verificação dos limites que separam um simples namoro de uma união estável ou homoafetiva, já que desde o início da relação há dependência econômica do(a) sugar baby em relação ao sugar daddy ou à sugar mammy.

O presente estudo, desenvolvido através de uma pesquisa qualitativa, interdisciplinar, essencialmente bibliográfica e documental, foi dividido em três partes: a primeira prestou-se à distinção fundamental entre contrato de namoro e contrato de convivência para, posteriormente, explanar-se sobre o contrato de relacionamento sugar; a segunda destinou-se à polêmica acerca da validade do contrato de namoro que não pode prestar-se a desqualificar uma união estável ou homoafetiva quando presentes os requisitos para configuração das mesmas, premissa que também se aplica aos contratos de relacionamento sugar; e, por fim, a terceira parte dedicou-se a cumprir o objetivo principal do trabalho, qual seja, demonstrar a importância da celebração de contratos de relacionamento sugar para que este fique muito bem caracterizado, com o intuito de que a dependência financeira nele verificada não seja usada, $a$ priori, como elemento a caracterizar judicialmente a existência de união estável ou homoafetiva quando no relacionamento não houver ânimo de ambas as partes de constituir família, devendo-se afastar, portanto, a aplicação do Princípio da Afetividade em tais situações fáticas.

\section{CONTRATO DE CONVIVÊNCIA E CONTRATO DE NAMORO}


Considerando que o presente estudo encontra substrato na interseção entre Direito de Família e Direito dos Contratos, é de suma importância conceituar estes últimos, expondo ao leitor conhecimentos essenciais ao estudo dos contratos de namoro e de convivência.

Em linhas gerais, pode-se dizer que o contrato reflete o "acordo de vontades por meio do qual as pessoas formam um vínculo jurídico a que se prendem” (GOMES, 1999, p. 6), devendo ser celebrado "na conformidade da lei, e com a finalidade de adquirir, resguardar, transferir, conservar, modificar ou extinguir direitos” (PEREIRA, 2017, p. 7). De forma mais completa, Diniz explica que

O contrato constitui uma espécie de negócio jurídico, de natureza bilateral ou plurilateral, dependendo, para a sua formação, do encontro da vontade das partes, por ser ato regulamentador de interesses privados. Deveras, a essência do negócio jurídico é a autorregulamentação dos interesses particulares, reconhecida pela ordem jurídica, que lhe dá força criativa. Num contrato, as partes contratantes acordam que se devem conduzir de determinado modo, uma em face da outra, combinando seus interesses, constituindo, modificando ou extinguindo obrigações (2017, p. 31).

Por sua vez, expressando a nova teoria contratual, Gagliano e Pamplona Filho aduzem que contrato “é um negócio jurídico por meio do qual as partes declarantes, limitadas pelos princípios da função social e da boa-fé objetiva, autodisciplinam os efeitos patrimoniais que pretendem atingir, segundo a autonomia das suas próprias vontades” (2006, p. 11). Da leitura deste último conceito constata-se estar o mesmo imbuído da principiologia que envolve a matéria na atualidade, consubstanciada na valorização da autonomia da vontade que encontra limites na função social dos contratos.

Excetuando-se a natureza peculiar dos contratos de adesão e aqueles cujo objeto consiste na prestação de serviço público concedido sob regime de monopólio, pode-se afirmar, via de regra, que o contrato nasce do consenso das partes que possuem livre arbítrio para decidirem, segundo seus interesses e conveniências, se, o quê, como e com quem desejam contratar e, portanto, deverá ser respeitado espontaneamente pelas mesmas através do exato cumprimento das obrigações por elas assumidas (pacta sunt servanda). Assim,

Como fonte criadora de direitos, o contrato assemelha-se à lei, embora de âmbito mais restrito. Os que contratam assumem, por momento, toda a força jurígena social. 


\section{RELACIONAMENTOS SUGAR E A PREOCUPAÇÃO DE QUE O INVESTIMENTO ECONÔMICO POSSA CONFIGURAR ERRONEAMENTE UNIÃO ESTÁVEL OU \\ HOMOAFETIVA}

Percebendo o poder obrigante do contrato, o contraente sente em si o impulso gerador da norma de comportamento social, e efetiva este impulso (PEREIRA, 2017, p. 11).

Contudo, frise-se que a liberdade de contratar não é absoluta e esbarra na imposição de que haja respeito à lei, aos bons costumes e observância à função social dos contratos.

A doutrina entende por bons costumes os que traduzem a moralidade social - e que, portanto, estão sujeitos a variações no espaço e no tempo - e não ofendam, por exemplo, “a opinião corrente no que se refere à moral sexual, ao respeito à pessoa humana, à liberdade de culto, à liberdade de contrair matrimônio” (PEREIRA, p. 24).

Relativamente ao dever de cumprimento da função social dos contratos, requisito expresso no art. 421 do Código Civil, pode-se afirmar que esta destina-se a limitar a autonomia da vontade quando esta colidir com o interesse social e este deva prevalecer (PEREIRA, 2017, p. 12).

Diante de tais premissas, importa identificar que os contratos possuem quatro elementos constitutivos, quais sejam: manifestação de vontade, agente, objeto (prestação obrigacional) e forma (veículo de condução da vontade). Diante da verificação dos mesmos, o contrato passa a existir enquanto negócio jurídico, mas há que se garantir que seja válido. “Os pressupostos de validade nada mais são do que os próprios elementos de existência adjetivados” (GAGLIANO; PAMPLONA FILHO, p. 20).

Desse modo, a manifestação de vontade não pode estar eivada de vício de consentimento, devendo ser livre e de boa-fé; aquele que manifesta sua vontade deve ser capaz; o objeto do contrato deve ser idôneo, lícito, não podendo ser vedado por lei; e a forma do contrato deve ser adequada, prevista ou não defesa em lei.

Finalmente, oportuno mencionar que embora normalmente os contratos comecem a produzir seus efeitos a partir da verificação de sua existência e validade, podem apresentar fatores eficaciais que limitam, de forma temporal, a produção de tais efeitos, dentre os quais três se destacam: o primeiro é o chamado termo, que consiste na fixação de um evento futuro e certo que protrai o começo da produção de efeitos do contrato ou faz cessá-los; o segundo é a condição, que diz respeito a acontecimento futuro e incerto que, caso ocorra, poderá dar início à produção de efeitos do contrato ou fazer cessá-los; e o encargo, que traduz-se em uma obrigação acessória incidental de negócios jurídicos gratuitos, que impõe ao beneficiário um ônus a ser cumprido. 
Feitas tais considerações prévias, passar-se-á à análise do contrato de namoro e do contrato de convivência, objetos deste capítulo.

Até a entrada em vigor da lei que regulamenta a união estável no Brasil (Lei 9278/96), bem como do Código Civil de 2002, a população poderia vivenciar relações amorosas sem que estas produzissem direitos de natureza patrimonial para os respectivos parceiros (FONSECA, 2009, p. 34).

A partir do momento em que a união estável passou a ser reconhecida judicialmente e posteriormente regulamentada por lei - conferindo à família de fato não só o respeito humano entre seus membros, mas, também, responsabilidades entre os mesmos derivadas da solidariedade familiar (AZEVEDO, 2011, p. 5) -, assistiu-se à preocupação da sociedade em geral em diferenciá-la do simples caso, namoro ou noivado com o intuito de que nestes últimos tipos de relacionamento amoroso não houvesse a produção de efeitos jurídicos, sobretudo patrimoniais. Assim, a legitimação da união estável enquanto forma de constituição de família fomentou, de um lado, o crescimento do número de contratos de convivência e, de outro, o surgimento da figura do contrato de namoro, diferenciando tais comportamentos.

Contrato de convivência é instrumento pelo qual o casal que compõe uma união estável promove a regulamentação dos reflexos da relação (CAHALI, 2002, p. 55), não se restringindo aos efeitos patrimoniais da mesma. Portanto, além de cláusulas relativas à administração do patrimônio, nada impede, por exemplo, que estipulem outras relativas a direitos previdenciários ou ao direito dos companheiros adotarem o sobrenome um do outro (DINIZ, 2017, p. 370).

Ressalte-se que referido instrumento não é obrigatório para que uma união estável reste configurada, nem pode ser tido como prova inequívoca da existência da mesma, sendo um indício de tal fato que, para ser verificado, deve revestir-se de exterioridade social.

Conforme esclarece o art. 1723 do Código Civil, para que haja a verificação fática da união estável há que se reunir os seguintes elementos: convivência pública, contínua e duradoura, estabelecida com o objetivo de constituição de família. Ademais, parte da doutrina fala em elementos acidentais, que facilitam a demonstração judicial deste tipo de relacionamento, a saber: tempo, prole e coabitação (GAGLIANO; PAMPLONA FILHO, 2015, p. 437).

A estes elementos Rizzardo acrescenta a "dependência efetiva de um companheiro ou convivente em relação ao outro” (2006, p. 890), a qual parece se enquadrar melhor na categoria de elemento acidental para a constituição da união estável. Frise-se que dependência econômica 


\section{RELACIONAMENTOS SUGAR E A PREOCUPAÇÃO DE QUE O INVESTIMENTO ECONÔMICO POSSA CONFIGURAR ERRONEAMENTE UNIÃO ESTÁVEL OU HOMOAFETIVA}

entre companheiros é presumida para fins de concessão de pensão por morte no âmbito previdenciário.

Também neste sentido, Oliveira (2008, p. 156) exemplifica que, além da dependência financeira, outros comportamentos que, por si só, não são requisitos para a constituição de uniões estáveis ou homoafetivas, podem contribuir para sua configuração, a saber: freqüência a lugares públicos conjuntamente; participação em reuniões, festividades e compromissos familiares; viagens em conjunto; abertura de conta bancária em comum; filho em comum; o tratamento dispensado por parentes, conhecidos, amigos; aquisição de bens em condomínio, dentre outros.

O namoro, em seu turno, é o relacionamento físico e psíquico que aspira continuidade e "traz ínsita a ideia de respeito mútuo e de fidelidade entre as pessoas envolvidas. Não significa estarem elas obrigadas a manter o caso, muito menos a caminho seguro do altar” (OLIVEIRA, 2006, p. 328).

Necessária a diferenciação entre namoro e união estável, "pois aquele resulta inteiramente do ambiente de liberdade, que a Constituição protege, inclusive da incidência de normas jurídicas, permanecendo no mundo dos fatos. Namorar não cria direitos e deveres” (TJRS, Apelação n. 70033655374, $7^{a}$ Câmara Cível, Rel. Des. José Conrado Kurtz de Souza, j. 26/05/2010). Enquanto no namoro há objetivo de constituir família futuramente, na união estável a família já está constituída.

Em tese, o contrato de namoro pode ser celebrado, encontrando fundamento no princípio da autonomia da vontade e no correlato poder de autorregulamentação dos interesses das partes contratantes que poderão criar contratos atípicos (sem previsão legal) para satisfazêlos. O objetivo dos contratos de namoro é afastar a produção de efeitos jurídicos decorrentes deste tipo de relacionamento.

\section{A POLÊMICA SOBRE A EFICÁCIA DO CONTRATO DE NAMORO}

Ainda que os namorados, quando maiores de idade, tenham a liberdade de celebrar contratos de namoro para afastar a configuração de união estável ou homoafetiva, considerando que estes dois últimos tipos de relacionamentos são atos-fatos jurídicos, a produção de efeitos jurídicos deles decorrentes não depende da vontade das partes neste sentido. Em outras palavras, mesmo havendo o contrato de namoro, caso os elementos configuradores de uma 
união estável ou homoafetiva sejam verificados na prática, assim serão tratados, não possuindo eficácia aquele contrato inicial.

A demonstração de existência de affectio familiae (ânimo presente de constituir família) entre duas pessoas é o elemento capaz de desnaturar o namoro e transformá-lo em união estável. Em decorrência deste elemento anímico, intencional, consistente no propósito de formação da família, evoca-se o Princípio da Afetividade, o qual garante a aplicação dos dispositivos (direitos e deveres) inerentes ao Direito de Família quando se está diante de uma “família de fato”.

Sobre o referido Princípio merece destaque suas duas dimensões: uma objetiva e outra subjetiva:

\begin{abstract}
A dimensão objetiva envolve a presença de fatos tidos como representativos de uma expressão de afetividade, ou seja, fatos sociais que indiquem a presença de uma manifestação afetiva. A dimensão subjetiva trata do afeto anímico em si, do sentimento de afeto propriamente dito. Essa dimensão subjetiva do principio certamente escapa ao direito, de modo que é sempre presumida, sendo que constatada a dimensão objetiva da afetividade restará, desde logo, presumida a presença da sua dimensão subjetiva. Dito de outro modo, é possível designá-lo como princípio da afetividade jurídica objetiva, o que ressalta o aspecto fático que é objeto da apreensão jurídica (CALDERÓN, 2013, p. 139).
\end{abstract}

Importante destacar que, a priori, o contrato de namoro pode ser considerado válido e lícito perante o ordenamento jurídico pátrio, desde que celebrado com o objetivo de documentar a realidade, seja em documento particular ou instrumento público, "só possuindo caráter de ilícito quando for usado para afastar regras de Direito de Família” (SILVA, 2004). Assim, ele só não produzirá efeitos jurídicos e, portanto, não terá eficácia, se o namoro evoluir e transmutar-se em união estável ou homoafetiva.

Se isto ocorrer, estar-se-á diante de ato-fato jurídico que seria de natureza não negocial, para o qual “a lei estabelece uma consequência jurídica sem observância do que foi desejado. Em decorrência, não lhe são aplicáveis, nem analogicamente, as prescrições sobre os negócios jurídicos ou declarações de vontade” ou seja, “pouco interessa a vontade declarada de se constituir família. A vontade encontra-se objetivada no agir das partes, podendo ser inferida por fatos vários, que não uma declaração de vontade” (BALBELA; STEINER, 2012, 


\section{RELACIONAMENTOS SUGAR E A PREOCUPAÇÃO DE QUE O INVESTIMENTO ECONÔMICO POSSA CONFIGURAR ERRONEAMENTE UNIÃO ESTÁVEL OU HOMOAFETIVA}

p. 9 e 20). Desse modo, sendo a família protegida constitucionalmente pelo Estado, "deve ser tutelada, independentemente da vontade das partes ou da forma pela qual a mesma tenha sido constituída” (FERREIRA, 2003, p. 73).

Nesses casos o contrato de namoro será válido, mas inidôneo para o fim desejado, já que a situação fática experimentada pelas partes produzirá efeitos que não poderão ser bloqueados por um negócio jurídico (FARIAS; ROSENVALD, 2012, p. 382-383).

Não concorda-se, portanto, que o contrato de namoro seja, de plano, algo inexistente e desprovido de eficácia no seio do ordenamento jurídico, conforme defende Dias (2009, p. 176), tampouco ilícito, já que, conforme explica Pereira, para que isso reste caracterizado, o objeto da obrigação deve envolver contrariedade à normação (2017, p. 31).

Parece mais acertado dizer que com a descaracterização do namoro a partir da detecção do ânimo de constituir família, pretender afastar a incidência do Princípio da Afetividade macularia o objeto da avença. Neste caso, o objeto deixaria de ser lícito - uma vez que “ilícitas serão as convenções que excluam os direitos de família” (MONTEIRO, 1981, p. 6) - e a aplicação do contrato tal qual como celebrado ensejaria enriquecimento ilícito daquele que insiste na configuração de mero namoro na tentativa de preservar para si o patrimônio constituído durante a união amorosa.

O entendimento aqui esposado é o que vem norteando a jurisprudência pátria que, a depender das circunstâncias fáticas presentes no caso concreto, confere ou não efetividade ao contrato de namoro. Assim,

o viver sob o mesmo teto, dormir na mesma cama, compartilhar a convivência familiar, seja para uma pessoa sinônimo de compromisso sério, próximo do estado de casado e, para outro, mero namoro, já que seu estilo de viver, sem hipocrisias e desfrutando da máxima liberdade, modela tal relacionamento como fruto de maturidade psicológica e não de comprometimento social. (...) talvez para garantir o entendimento claro das intenções e o modo de ser e pensar, é que tais contratos estejam sendo utilizados em maior escala (COL, 2004, p. 143).

A 9a Câmara de Direito Privado do Tribunal de Justiça do Estado de São Paulo se manifestou sobre o tema ao julgar um recurso de apelação em uma ação movida com a finalidade de se reconhecer a alegada união estável entre um casal e, reflexamente, do direito à partilha de bens e aos alimentos. O relator do acórdão confirmou a sentença de primeira 
instância ao entender que não se tratava de uma união estável, mas de um namoro. Considerou como elementos probatórios o fato do casal ter convivido por apenas seis meses, por dormirem em casas separadas, exceto aos finais de semana e assinado um contrato de namoro: "Verificase que os litigantes convencionaram um verdadeiro contrato de namoro, celebrado em janeiro de 2005, cujo objeto e cláusulas não revelam ânimo de constituir família” (gn) (TJSP, Apelação n. 9103963-90.2008.8.26.0000, 9a Câmara de Direito Privado, Rel. Des. Grava Brazil, j. 12/08/2008).

\section{O CONTRATO DE RELACIONAMENTO SUGAR}

Conforme exposto brevemente na introdução deste estudo, por muito tempo os relacionamentos amorosos tiveram como objetivo não a realização pessoal e os sentimentos dos envolvidos, mas eram expressão de elementos culturais de épocas passadas em que, por exemplo, as trocas de pessoas pertencentes a famílias estranhas entre si eram importantes para formar alianças e agregar patrimônio.

A Antropologia explica esta dinâmica através da Teoria da Dádiva, segundo a qual a sociabilidade é construída e mantida através dos comportamentos dar-receber-retribuir, por meio de transações que mobilizam "itens de várias espécies, incluindo homens e mulheres, como posses ou recursos à disposição do negociador” (STRATHERN, 2006, p. 22). “A troca não vale somente o que valem as coisas trocadas”, possuindo valor social (LÉVI-STRAUSS, 2009, p. 523).

Com o passar do tempo, principalmente com a conversão das famílias numerosas em famílias nucleares, estas, enquanto instituições, paulatinamente assistiram à sua importância ser deslocada para os membros que a compõem, importância esta que aumentou proporcionalmente à valorização da dignidade da pessoa humana pelo Direito e pela sociedade. Neste contexto, os sentimentos e desejos das pessoas passaram a importar e a nortear a forma como os relacionamentos amorosos se constituiriam, reflexo do respeito à autonomia da vontade de cada indivíduo.

Contextualizando esta autonomia na atualidade, a escolha dos relacionamentos amorosos passou a pautar-se, cada vez mais, na busca da felicidade e do prazer, desejos cuja consecução interfere na durabilidade das relações. Neste cenário importa destacar o amor puro ou confluente descrito por Guiddens (1993): 


\section{RELACIONAMENTOS SUGAR E A PREOCUPAÇÃO DE QUE O INVESTIMENTO ECONÔMICO POSSA CONFIGURAR ERRONEAMENTE UNIÃO ESTÁVEL OU HOMOAFETIVA}

Refere-se a uma situação em que se entra em uma relação social apenas pela própria relação, pelo que pode ser derivado por cada pessoa da manutenção de uma associação com outra, e que só continua enquanto ambas as partes considerarem que extraem dela satisfações suficientes, para cada uma individualmente, para nela permanecerem (p. 68). (...) O amor confluente é um amor ativo, contingente, e por isso entra em choque com as categorias “para sempre” e "único” da ideia do amor romântico. (...) Quanto mais o amor confluente consolida-se em uma possibilidade real, mais se afasta da busca da “pessoa especial” e o que mais conta é o “relacionamento especial” (p. 72).

(...) O que mantém o relacionamento puro é a aceitação, por parte de cada um dos parceiros, “até segunda ordem”, de que cada um obtenha da relação benefício suficiente que justifique a continuidade” (p. 74).

Este tipo de relacionamento parece ideal para atender aos anseios das gerações mais recentes, cada vez mais egoístas, egocêntricas e, considerando sua liberdade de escolha praticamente ilimitada, altamente exigentes (BAKAS, 2011, p. 100). Não se pode olvidar que tais características são ditadas pela lógica do capital que, para além de influenciar a política e a economia, rege os relacionamentos sociais como um todo, inclusive os de cunho amoroso.

“O capitalismo afetivo é uma cultura em que os discursos e práticas afetivos e econômicos moldam uns aos outros (...) e no qual a vida afetiva - especialmente a da classe média - segue a lógica das relações econômicas e da troca” (ILLOUZ, 2011, p. 12), de forma que a "escolha de parceiros afetivos está cada vez mais circunscrita a reflexões da ordem do “custo benefício”, revelando mecanismos de cálculo e investimento que, outrora, caracterizariam transações financeiras, práticas contratuais e performances de rendimento” (GIRARDELO, 2016).

Frise-se, contudo, existir um tabu contra a mistura entre relações pessoais íntimas e condução de atividade econômica pautado na crença de que esta corrompe aquela e vice-versa (ZELIZER, 2011, p. 13). Diante desta constatação, pode-se afirmar que os relacionamentos sugar, explicitados no intróito deste estudo, profanam este tabu ao devolverem à sociedade algo que "historicamente foi retirado do uso comum por meio de movimentos de sacralização, sem permitir que o uso/sentido originário possa ser recuperado integralmente, mas proporcionandolhe um novo uso (AGAMBEN, 2007, p. 10). 
Diante desta possibilidade de retomada dos relacionamentos baseados explicitamente no interesse financeiro sem que isso cause constrangimento entre os amantes, como já ocorreu no passado, “deveríamos prestar atenção à advertência de Derrida e estar cientes de que só podemos usar velhos conceitos, inevitavelmente repletos de significados ultrapassados, fazendo-se neles as emendas necessárias” (BAUMAN, 2005, p. 62).

Portanto, importante esclarecer que se no passado os relacionamentos amorosos visavam alianças patrimoniais decorrentes das trocas de pessoas com o objetivo de fortalecimento das famílias, a proposta dos relacionamentos sugar tem como objetivo a realização pessoal decorrente da troca que se aperfeiçoa entre as partes. Ainda que uma das partes esteja inicialmente imbuída de interesse financeiro, o caráter personalista da relação suplanta o patrimonialista e atrela-se à ideia de amor puro ou confluente de Guiddens.

Há que se desmistificar a palavra “interesse”, avalorativa em sua gênese, e que move todas as pessoas, em todas relações. No âmbito dos relacionamentos sugar, interesse consiste simplesmente na vontade de estar com, nada mais (SIMÃO, 2017), sendo certo que uma das partes busca amparo e segurança financeira e a outra, em contrapartida, busca sedução, juventude e estética. O interesse econômico não é nem mais nem menos louvável do que outros verificáveis neste contexto, como os de ordem afetiva e sexual. É necessário, portanto, "enfrentar a dificuldade que temos em considerar de forma imparcial interesses de ordem distinta” (GROENINGA, 2017).

Ainda que os relacionamentos sugar possam parecer uma novidade, Zelizer (2011, p. 103) relata que

Analisando a prática do caso na cidade de Nova York entre 1900 e 1932, Elizabeth Clement afirma que "as jovens trocavam favores sexuais pelo jantar e pela despesas da noite, ou, de modo mais tangível, por meias, sapatos e outros bens de consumo” (CLEMENT, 1998a:68). Essas mulheres, ela observa, usavam os casos "para conseguir entrar no mundo caro das diversões urbanas e distinguir-se das prostitutas que moravam e trabalhavam nos seus bares”. Contrastando com as prostitutas, essas mulheres e seu companheiros estabeleceram uma espécie de economia de presentes. Clement explica: “Elas não somente recusavam dinheiro, como também não trocavam serviços por bens materiais. Ao contrário, recebiam presentes dos seus amigos” (120). (...) Apesar do fato de a mulher receber presentes e serviços de valor, o caso não a qualificava como trabalhadora do sexo, não identificava seu companheiro como cliente, nem a impedia de ganhar a vida por meio de formas de trabalho não sexuais. 
Neste sentido, oportuno transcrever uma citação de Miranda publicada em 1984 para defender a desnecessidade da economicidade do objeto do contrato para que o mesmo seja válido. Embora o autor obviamente não estivesse a se referir aos relacionamentos sugar, sua descrição ilustrou muito bem aquela troca de favores esperada neste tipo de relação. Para o mesmo, a prestação devida pode não ter qualquer valor material, “como se A obtém de B que o acompanhe ao teatro por ser B de alta família. Nem o interesse é patrimonial, nem a prestação é de valor patrimonial, nem há ilicitude na promessa” (1984, p. 40). Embora seja esta uma situação hipotética, certamente era uma prática comum no passado, tanto que foi utilizada para exemplificar o posicionamento daquele doutrinador. Assim, enquanto um pólo da relação contratual era ocupado por alguém da high society, no outro normalmente existia um(a) jovem esteticamente aprazível que se beneficiaria da companhia pública daquele, em busca de status, visibilidade e networking.

Nota-se que este tipo de comportamento bem como a economia de presentes praticada outrora foram atualmente potencializados pelas redes sociais e os contatos estabelecidos por intermédio das mesmas, fazendo prosperar os relacionamentos sugar.

\footnotetext{
Nesta era tecnológica, de comunicações imediatas, conhecimento de centenas de pessoas no mundo virtual, pressão social e profissional e um sem-número de normas legais a serem obedecidas, era inevitável que as relações afetivas fossem afetadas e se transformassem. O velho e tradicional namoro, situação prévia para o casamento, que apontava para um noivado antecedente, desapareceu tal como era algumas décadas atrás. As velhas regras sociais e freios sexuais do passado não existem mais. As inúmeras regras que impõem novos deveres sociais, morais e responsabilidade patrimonial aos envolvidos em um relacionamento afetivo forçam cada dia mais uma nova perspectiva nessa área de convivência (VENOSA, 2012, p. 335).
}

Nesta nova perspectiva, a intimidade como exigência de relação emocional constante pode ser sufocante, opressiva, ao passo que vista "como uma negociação transacional de vínculos pessoais, estabelecida por iguais, ela surge sob uma luz completamente diferente” (GUIDDENS, 1993, p. 11).

O prazer e o imediatismo sedutoramente tomam o lugar dos relacionamentos tradicionais, assumindo modelos baseados em relações menos profundas, mais efêmeras, 
marcadas pela comunhão parcial de alguns interesses não necessariamente duradouros e, às vezes talvez, mas não necessariamente, mais desumanizadas (GROENINGA, 2017).

Os sites que promovem relacionamentos sugar colocam em contato pessoas que concordam com a dinâmica deste tipo de relação para que encontrem potenciais parceiros e estabeleçam negociações no sentido de impulsionar a economia dos presentes entre si, ilustrando de forma clara a mecânica social do dar, receber e retribuir consubstanciada na Teoria da Dádiva.

Conforme explica o site www.universosugar.com, as relações em tela são mutuamente benéficas: a pessoa que ocupa a posição de sugar baby terá proteção, conforto, e segurança financeira proporcionadas por um sugar daddy ou uma sugar mammy experiente, inteligente, maduro(a), sofisticado(a), bem-sucedido(a) e generoso(a) que compartilhará bons momentos e experiências com uma companhia jovem, atraente e divertida que busca sucesso profissional e pessoal, presentes, viagens e uma vida sem preocupações.

Embora não se tratem de relacionamentos casuais, estão longe de cumprir os protocolos típicos dos namoros, estando pautados na liberdade. O objetivo é que ambas as partes tenham suas expectativas atendidas sem quaisquer compromissos rígidos.

O site $\underline{w w w . m e u p a t r o c i n i o . c o m}$ deixa claro que nos relacionamentos em questão a pessoa sabe exatamente o que quer de um(a) parceiro(a) e a relação se desenvolverá da maneira que desejar, podendo os contraentes, por exemplo, serem apenas amigos esperando que a atração cresça. Há pessoas que procuram namoros imediatos, outras buscam relacionamento sem compromisso.

Cabe aos envolvidos descobrir e formatar o que querem um do outro, afastando expectativas que geram frustração quando não atingidas, de forma que “o esclarecimento dos valores e metas do sujeito, o uso da técnica do cálculo e a descontextualização e objetificação dos sentimentos, tudo isso acarreta uma intelectualização dos laços íntimos” (ILLOUZ, 2011, p. 52).

Frise-se que embora pareça fácil esta objetivação dos sentimentos e dos relacionamentos, estes, inevitavelmente, geram expectativas, conscientes ou não. “Queiramos ou não, somos seres temporais e desejantes, para além da satisfação de meras necessidades, de forma que acaba sendo contraditória a ideia de estar junto e nada mais” (GROENINGA, 2017).

É fato que o relacionamento superficial instaurado inicialmente pode evoluir para graus maiores de envolvimento até a configuração fática de uma união estável ou homoafetiva. 


\title{
RELACIONAMENTOS SUGAR E A PREOCUPAÇÃO DE QUE O INVESTIMENTO ECONÔMICO POSSA CONFIGURAR ERRONEAMENTE UNIÃO ESTÁVEL OU HOMOAFETIVA
}

Há relatos neste sentido na internet demonstrando que tais relações não são, necessariamente, casuais. É o caso da sugar baby Fernanda e do sugar daddy Jairo:

\begin{abstract}
"Resolvemos nos encontrar pessoalmente pouco tempo depois do primeiro contato", relembra Jairo. Fernanda, que na época tinha 22 anos, viajou de Criciúma (SC) para Porto Alegre para conhecer Jairo. Quinze dias após o primeiro encontro, veio o segundo e depois o terceiro... e as viagens quinzenais da catarinense viraram rotina. "Costumo dizer que a gente se encontrou. Nos damos muito bem, nossa relação é bem tranquila”, comenta. Em janeiro, o casal descobriu que Fernanda estava grávida e ela foi morar com Jairo em Porto Alegre. Catherine nasceu dia 14 de julho, menos de um ano após os pais se encontrarem no site Meu Patrocínio, e já tem uma importante missão pela frente. Assim que aprender a andar, será a daminha de honra no casamento religioso dos pais. "No civil, casamos agora em setembro. A Fernanda é a mulher que quero ficar para o resto da minha vida”, diz Jairo (YOBA, 2017).
\end{abstract}

Considerando a possibilidade de que os relacionamentos sugar possam vir a se perpetuar no tempo, tornando-se duradouros, o fato de a dependência econômica ser um dos fatores que embalam a parceria poderia ser um elemento usado de má-fé para forçar a configuração de uma união estável ou homoafetiva que não existe efetivamente.

Conforme destaca Calderón, “é possível vislumbrar que a afetividade jurídica envolve atos de cuidado, de subsistência, de carinho, de educação, de suporte psíquico e emocional, de entreajuda, de comunhão de vida, entre outros” (2013, p. 139). O autor destaca elementos que, reunidos, presentes em menor ou maior intensidade no substrato fático de um caso concreto, autorizam que o Princípio da Afetividade seja evocado para que àquele sejam aplicados os efeitos jurídicos inerentes ao Direito de Família.

Excetuando a comunhão de vida que, no contexto jurídico, traduz-se em ânimo/vontade de constituir família, os demais elementos acima elencados podem ser facilmente vislumbrados em um relacionamento sugar recém iniciado, sem que o affectio familiae esteja presente. Com relação a prover educação, é muito comum que o(a) sugar baby tenha seus estudos patrocinados pelo sugar daddy ou pela sugar mammy que também dão suporte emocional àqueles.

Neste contexto é de suma importância a discussão acerca do contrato de relacionamento sugar, que não deve ficar circunscrito ao preenchimento dos dados solicitados 
pelo site que promove o encontro entre as pessoas, bem como à adesão aos termos e condições de uso e política de privacidade exigidos no momento do cadastramento.

Tudo o que foi explanado anteriormente neste estudo sobre os contratos de namoro é aplicável ao contrato de relacionamento sugar. Ainda que paire polêmica sobre a validade e a eficácia do contrato de namoro, conforme demonstrou-se, não se vislumbra melhor opção para tentar garantir a verdade dos fatos do que a contratação, também por escrito, dos relacionamentos sugar, demonstrando que a dependência econômica do(a) sugar baby é uma premissa da relação e que os mimos e serviços proporcionados pelo sugar daddy ou pela sugar mammy não podem ser interpretados, de plano, como prova de que o relacionamento é estável em razão de uma das partes ser sustentada pela outra.

A dependência financeira, portanto, precisa ser vista com parcimônia pelo julgador, uma vez que este está acostumado a analisar relacionamentos tradicionais em que aquela é, sim, um fator que ajuda a formar sua convicção acerca da existência de um relacionamento amoroso em que há ânimo de constituir família. Se o contrato de relacionamento sugar tiver sido celebrado terá o condão de fazer com que o magistrado consiga ter a correta visão da dependência econômica no caso levado sob sua apreciação.

Para se ter a dimensão desta dependência que certamente pode ser mal interpretada como elemento configurador de união estável ou homoafetiva, oportuno transcrever os seguintes comentários extraídos do site www.universosugar.com:

\begin{abstract}
Quanto vou receber do Sugar Daddy no relacionamento sugar? Muitas Babies fazem esse questionamento em grupos do Facebook. E como nossa missão aqui no blog do Universo Sugar é orientar e abordar de forma educativa o conceito desse estilo de vida, fique sabendo que não há valores fixos de mesadas para Sugar Babies, e sim expectativas. O valor em média de benefícios recebidos por mês, é de aproximadamente R\$3.000,00. Entretanto, esses valores variam de R \$ 500,00 a R\$ $5.000,00$. Depende muito dos lugares em que os casais estão localizados. Existem cidades com o custo de vida maior. Algumas regiões são mais prósperas outras não. Tudo isso deve ser levado em consideração na hora falar sobre essa média. E quando falamos em R\$3.000,00, não significa que no final do mês você receberá esse valor em cash (espécie). Há casos em que de fato as babies recebem uma mesada. Em outros, a ajuda financeira vem através do pagamento de despesas como, por exemplo, mensalidade da faculdade, aluguel, prestações atrasadas ou gastos com estética e academia. E acredite, até financiamento de projetos pessoais e profissionais.
\end{abstract}

Diante do exposto, o contrato de relacionamento sugar se presta a demonstrar que a relação já se inicia, desde o primeiro dia, com dependência econômica de uma das parte em 


\section{RELACIONAMENTOS SUGAR E A PREOCUPAÇÃO DE QUE O INVESTIMENTO ECONÔMICO POSSA CONFIGURAR ERRONEAMENTE UNIÃO ESTÁVEL OU HOMOAFETIVA}

relação à outra, característica esta que dificilmente será observada em outros tipos de união. Esta atipicidade precisa ficar muito bem caracterizada para não ser interpretada erroneamente em sede judicial.

O relacionamento sugar está mais para um instrumento promotor de um estilo de vida do que para um relacionamento amoroso propriamente dito e é isso que se pretende deixar registrado no respectivo contrato. Logicamente que, não obstante a existência deste instrumento, não produzirá efeitos jurídicos para afastar a incidência do Princípio da Afetividade se a relação evoluir para um patamar de envolvimento do qual possa ser extraído o ânimo de constituir família.

De qualquer forma, ainda que o receio da errônea configuração de união estável ou homoafetiva seja maior nos relacionamentos sugar do que em um namoro comum, o contrato para elucidar a existência dos mesmos provavelmente enfrentará obstáculos não enfrentados pelo contrato de namoro, pois há quem atrele a licitude do objeto contratado à moral, a exemplo de Venosa, para quem a avença deve atender aos ditames da moral e dos bons costumes sob pena de nulidade, considerando ilícito a elaboração de contrato para manutenção de relações sexuais e a contratação de casamento em troca de vantagens pecuniárias (2017, p. 17). No mesmo sentido, Monteiro considera ilícito o “chamado casamento por contrato e pelo qual o homem e a mulher combinam viver debaixo do mesmo teto, por tempo indeterminado, como se realmente consorciados, em troca de determinadas vantagens” (1981. p.6).

\section{CONSIDERAÇÕES FINAIS}

“O dinheiro compra até o amor verdadeiro”, já dizia o escritor Nelson Rodrigues. Com base neste pensamento desenvolveu-se o presente estudo que pretendeu apresentar a figura do contrato de relacionamento sugar, muito similar ao já conhecido contrato de namoro, como forma de tentar afastar a configuração judicial errônea de uniões estáveis ou homoafetivas que efetivamente não existem.

Conforme demonstrou-se, neste tipo de relação o papel do sugar daddy e da sugar mammy reside em proporcionar um estilo de vida sofisticado e confortável ao(à) sugar baby, podendo arcar, inclusive com a realização de projetos pessoais ou profissionais. 
Os sites que promovem este tipo de relação deixam claro que a mesma se constitui com o objetivo de que alguém que deseja apoio financeiro está disposto(a) a ser uma companhia interessante e agradável para quem o(a) está patrocinando. Patrocínio

Sugar daddies e sugar mammies precisam, ao se cadastrem nestes portais, informarem sua renda e este valor será determinante para a aprovação da ficha cadastral dessas pessoas, já que precisam conseguir suportar o estilo de vida característico do universo sugar. Patrocinar alguém é uma estratégia de investimento. Envolve a provisão de recursos financeiros, humanos ou físicos em troca de algo.

Demonstrou-se que, pelo menos quando iniciadas, as relações sugar mais se assemelham ao patrocínio deste estilo de vida baseado na "economia dos presentes" e sustentado por um patrocinador do que a um relacionamento amoroso propriamente dito.

Diante da ostentação pública, contínua e duradoura de manifestações de carinho, cuidado, mimo e dependência financeira, é muito tênue o limite entre a exteriorização de um relacionamento sugar e de uma união estável ou homoafetiva.

Assim, a mesma crítica feita aos contratos de namoro precisa ser traçada aos contratos de relacionamento sugar: se o mesmo evoluir em termos de compromisso e intensidade a ponto de o elemento affectio familiae puder ser constatado, a avença não terá validade - dada a desnaturação do objeto contratado - passando o relacionamento a ser tratado judicialmente como união estável ou homoafetiva, passando o casal a desfrutar dos direitos e obrigações inerentes ao Direito de Família.

Ainda que possa haver (e há) reprovação moral acerca do estilo de vida sugar, as relações firmadas neste âmbito não se constituem no campo da ilicitude e, decerto, o enfrentamento da questão pelo Direito dos Contratos e pelo Direito de Família precisa se dar de forma lúcida, sem moralismos que em nada contribuem para um debate tão importante sobre a constituição ou não de vínculos familiares.

\section{REFERÊNCIAS}

AGAMBEN, Giorgio. Profanações. Tradução de Selvino J. Assmann. São Paulo: Boitempo, 2007.

AZEVEDO, Álvaro Villaça. Estatuto da família de fato. 3ª ed. São Paulo: Atlas, 2011. 
BAKAS, Adjiedj. O futuro do amor - intimidade, sexo, união e solidão na nova ordem mundial. Tradução de Silmara Oliveira. São Paulo: A Girafa, 2011.

BALBELA, João Rubens Pires; STEINER, Renata Carlos. União estável como ato-fato: importância da classificação. In: Revista Brasileira de Direito das Famílias e Sucessões, ano XIV, n. 28, jun/jul 2012, Porto Alegre, Magister, p. 5-21.

BAUMAN, Zygmunt. Identidade - entrevista a Benedetto Vecchi. Tradução de Carlos Alberto Medeiros. Rio de Janeiro: Zahar, 2005.

CAHALI, Francisco José. Contrato de Convivência na União Estável. São Paulo: Saraiva, 2002.

CALDERÓN, Ricardo Lucas. Princípio da afetividade no direito de família. In: Revista Brasileira de Direito das Famílias e Sucessões, ano VI, n. 23, abr/mai 2004, Porto Alegre, Magister, p. 129-141.

COL, Helder Martins Dal. Contratos de namoro. In: Revista Brasileira de Direito das Famílias e Sucessões, ano XV, n. 35, ago/set 2013, Porto Alegre, Síntese, p.126-156.

DIAS, Maria Berenice. Manual de direito das famílias. 5ª ed. rev., atual. e ampl. São Paulo: Editora Revista dos Tribunais, 2009.

DINIZ, Maria Helena. Curso de Direito Civil Brasileiro - Teoria das obrigações contratuais e extracontratuais. Vol. 3. 33. Ed. São Paulo: Saraiva, 2017.

FARIAS, Cristiano Chaves de; ROSENVALD, Nelson. Curso de direito civil: direito das famílias. 4a. ed. Salvador: Juspodivm, 2012.

FERREIRA, Fábio Alves. O reconhecimento da união de fato como entidade familiar e sua transformação num casamento não solene. Rio de Janeiro: Lumen Juris, 2003. 
FONSECA, Priscila M. P. Corrêa da. O direito ao amor não oneroso. In: Revista Brasileira de Direito das Famílias e Sucessões, ano XI, n. 10, jun/jul 2009, Porto Alegre, Magister, p. 3439.

GAGLIANO, Pablo Stolze; PAMPLONA FILHO, Rodolfo. Novo Curso de Direito Civil, Vol. 4. $2^{\text {a }}$. ed. São Paulo: Saraiva, 2006.

Novo Curso de Direito Civil, Vol. 6. 5 . ed. rev. e atual. São Paulo: Saraiva, 2015.

GIRARDELO, Luiza. Sugar daddies e sugar babies: uma análise sobre o capital social na plataforma online Meu Patrocínio (2016). Disponível em: http://anaiscomunicon2016.espm.br/GTs/GTGRAD/GT1/GT01-LUIZA_GIRARDELLO.pdf. Acesso em: 17/03/2018.

GOMES, Orlando. Contratos. 14. Ed. Rio de Janeiro: Forense, 1999.

GROENINGA, Giselle Câmara. Sugar daddy e sugar baby: transparência nas relações afetivas (parte 2) (2017). Disponível em: https://www.conjur.com.br/2017-jan-22/sugar-daddy-sugarbaby-transparencia-relacoes-afetivas-parte. Acesso em: 14/01/2018.

GUIDDENS, Anthony. A transformação da intimidade - sexualidade, amor e erotismo nas sociedades modernas. Tradução de Magda Lopes. São Paulo: UNESP, 1993.

ILLOUZ, Eva. O amor nos tempos do capitalismo. Tradução de Vera Ribeiro. Rio de Janeiro: Zahar, 2011.

LÉVI-STRAUSS, Claude. As estruturas elementares do parentesco. Tradução de Mariano Ferreira, 5a . ed. Petrópolis: Vozes, 2009.

MIRANDA, Pontes de. Tratada do Direito Privado - Parte Especial. Tomo XXII. $3^{\text {a }}$ Ed. São Paulo: Revista dos Tribunais, 1984. 
MONTEIRO, Washington de Barros. Curso de Direito Civil: Direito das Obrigações. $2^{a}$ parte. $16^{\mathrm{a}}$ ed. São Paulo: Saraiva, 1981.

OLIVEIRA, Euclides. A escalada do afeto do direito de família: ficar, namorar, conviver, casar. In: PEREIRA, Rodrigo da Cunha (Coord.). Família e dignidade humana. Belo Horizonte: IBDFAM, 2006, p. 315-346.

- União estável: conceituação e efeitos jurídicos. In: BARBOSA, Águida Arruda; VIEIRA, Claudia Stein (Coords.). Direto Civil, vol. 7: direito de família. São Paulo: Editora Revista dos Tribunais, 2008, p. 150-170.

PEREIRA, Caio Mario da Silva. Instituições de Direito Civil - Vol. III. Contratos. 21. ed. Rio de Janeiro: Forense, 2017.

RIZZARDO, Arnaldo. Direito de Família: Lei $\mathrm{n}^{\circ} 10.406$ de 10.01.2002. Rio de Janeiro: Forense, 2006.

SILVA, Regina Beatriz Tavares da. O mal falado contrato de namoro (2004). Disponível em: $<$ http://www.reginabeatriz.com.br/academico/artigos/artigo.aspx?id=130>. Acesso em: 20/02/2018.

SIMÃO, José Fernando. Sugar daddy e sugar baby: transparência nas relações afetivas (parte 1) (2017). Disponível em: https://www.conjur.com.br/2017-jan-08/sugar-daddy-sugar-babytransparencia-relacoes-parte. Acesso em: 14/01/2018.

STRATHERN, Marilyn. O Gênero da dádiva - problemas com as mulheres e problemas com a sociedade na Melanésia. Tradução de André Villalobos. Campinas: UNICAMP, 2006.

TJRS, Apelação n. 70033655374, 7ª Câmara Cível, Rel. Des. José Conrado Kurtz de Souza, j. $26 / 05 / 2010$ 
TJSP, Apelação n. 9103963-90.2008.8.26.0000, $9^{\text {a }}$ Câmara de Direito Privado, Rel. Des. Grava Brazil, j. 12/08/2008.

VENOSA, Silvio de Salvo. Contratos Afetivos: o temor do amor. In: PEREIRA, Rodrigo da Cunha (Coord.). Família - entre o público e o privado. Porto Alegre: Magister/IBDFAM, 2012, p. 334-337.

Direito Civil, Vol. 2: Obrigações e Responsabilidade Civil, 18 a edição. Atlas, 12/2017, VitalBook file.

YOBA. Dinheiro não traz felicidade? Sugar Daddy comemora nascimento de filha com Sugar Baby. Disponível em: https://yoba.com.br/17/2017/08/03/site-de-homens-ricos-e-mulheresatraentes-tem-primeiro-dia-dos-pais-com-bebe/ . acesso em: 23/03/2018.

ZELIZER, Viviana A. A negociação da intimidade. Tradução de Daniela Barbosa Henriques. Petrópolis: Vozes, 2011. 